\title{
Predominant methyl radical initiation preceded by $\beta$-scission of alkoxy radicals in allyl polymerization with organic peroxide initiators at elevated temperatures
}

\author{
Satoshi Inoue ${ }^{1,2}$, Takeo Kumagai ${ }^{1}$, Hajime Tamezawa ${ }^{1}$, Hiroyuki Aota ${ }^{1}$, Akira Matsumoto ${ }^{1}$, \\ Katsutoshi Yokoyama ${ }^{2}$, Yasuo Matoba ${ }^{2}$ and Michirou Shibano ${ }^{2}$
}

Allyl monomers polymerize with difficulty and their polymerization yields polymers of medium molecular weight or oligomers. Matrix-assisted laser desorption/ionization time-of-flight mass spectrometry is a powerful tool for structural identification of oligomers; therefore, we aimed to use it to collect direct evidence for a full mechanistic discussion, including initiation and termination reactions. In the course of our investigation, which was concerned with the temperature dependence of the reinitiation reactivity of resonance-stabilized monomeric allyl radicals and was especially focused on polymerization behavior at elevated temperatures, we found by chance that any direct contribution of cumyloxy radicals to the initiation reaction was not observed in the polymerization of allyl benzoate with dicumyl peroxide (a typical peroxide initiator) at elevated temperatures. However, a methyl radical initiation preceded by $\beta$-scission of cumyloxy radicals predominantly occurred. This finding was extended to the generalization of an initiation reaction mechanism in allyl polymerization with organic peroxide initiators at elevated temperatures.

Polymer Journal (2010) 42, 716-721; doi:10.1038/pj.2010.66; published online 4 August 2010

Keywords: alkoxy radical; allyl polymerization; initiation; MALDI-TOF-MS; methyl radical; organic peroxide initiator

\section{INTRODUCTION}

Allyl monomers polymerize with difficulty and their polymerization yields polymers of medium molecular weight or oligomers. ${ }^{1-4}$ This is attributable to 'degradative monomer chain transfer.' ${ }^{5-7}$ The wellknown allyl polymerization mechanism ${ }^{8-13}$ is based on kinetic data alone, without structural identification. In our preceding study, ${ }^{14}$ allyl acetate (AAc), a typical allyl monomer, was polymerized radically, and the resulting oligomeric poly(AAc)s were characterized using matrixassisted laser desorption/ionization time-of-flight mass spectrometry (MALDI-TOF-MS) to reassess the AAc polymerization mechanism proposed by Litt and Eirich; ${ }^{13}$ their mechanism was based on results reported in the period 1940-1960. We propose a renewal of the wellknown reaction scheme for the free-radical polymerization of AAc. On the basis of this renewed reaction mechanism, which yields oligomers, we investigated the fate of resonance-stabilized monomeric allyl radicals as follows. The coupling termination of monomeric allyl radicals with growing polymer radicals, leading to a shortening of the oligomeric poly(AAc) chain length, was significant under a common allyl polymerization condition, in which a remarkably large amount of initiator was used compared with common vinyl polymerization.
Under the completely opposite condition, in which polymerization was carried out at a low initiator concentration, the reinitiation reaction of monomeric allyl radicals occurred predominantly without any contribution from the monomeric allyl radical to the coupling termination reaction with growing polymer radicals. The latter reinitiation reaction of monomeric allyl radicals is significant because in allyl polymerization, it is conceivable that the resulting monomeric allyl radical is less active and/or less inclined to initiate a new polymer chain because of an ability to stabilize itself by resonance-the monomer chain transfer is essentially a termination reaction. Our investigation was concerned with the temperature dependence of the reinitiation reactivity of resonance-stabilized monomeric allyl radicals and was especially focused on polymerization behavior at elevated temperatures. We found by chance that any peak assignable to cumyloxy radical initiation was not observed in the MALDI-TOF-MS spectrum of the resulting oligomer in the free-radical polymerization of $\mathrm{ABz}$, with $\mathrm{DCPO}$ as one of the typical peroxide initiators at $130^{\circ} \mathrm{C}$. However, initiation by methyl radical generation by $\beta$-scission of cumyloxy radicals predominantly occurred. This finding with DCPO was extended to other initiators such as $t$-butyl peroxybenzoate (BPOB)

${ }^{1}$ Department of Chemistry and Materials Engineering, Faculty of Chemistry, Materials and Bioengineering and High Technology Research Center, Kansai University, Suita-shi, Osaka, Japan and ${ }^{2}$ Technical Development Department, Chemical Specialties Division, Daiso Co., Ltd., Amagasaki-shi, Hyogo, Japan

Correspondence: Professor A Matsumoto, Department of Chemistry and Materials Engineering, Materials and Bioengineering and High Technology Research Center, Kansai University, 3-3-35 Yamate-cho, Suita-shi, Osaka 564-8680, Japan.

E-mail: amatsu@kansai-u.ac.jp

Received 6 March 2010; revised 7 May 2010; accepted 15 June 2010; published online 4 August 2010 
and di-t-butyl peroxide (DBPO) for generalization of this interesting initiation behavior of organic peroxides at elevated temperatures.

It is noteworthy that approximately 100 organic peroxide initiators are commercially produced throughout the world, primarily for polymer and resin industries. DCPO, BPOB and DBPO are typical organic peroxides used as initiators to generate radicals at elevated temperatures, being useful for vinyl monomer polymerizations, curing of unsaturated polyester and diallyl phthalate (DAP) resins, crosslinking of elastomers and polyolefins, and for reactive extrusion. ${ }^{15,16}$

\section{EXPERIMENTAL PROCEDURE}

\section{Materials}

$\mathrm{ABz}$ (Daiso Co., Ltd., Osaka, Japan), as a monomer, was purified by vacuum distillation under nitrogen. DCPO, BPOB and DBPO (NOF Corp., Aichi, Japan), as initiators, were used without further purification.

2,5-Dihydroxybenzoic acid (DHBA; Sigma-Aldrich, Milwaukee, WI, USA), as a matrix, sodium iodide (NaI; Wako Pure Chemical Industries Ltd., Osaka, Japan), as a cationizing agent, and polyethylene glycol (PEG, $M_{\mathrm{w}}=2000 \mathrm{Da}$; Wako Pure Chemical Industries Ltd.) were purchased and used.

\section{Polymerization}

Polymerization was carried out in a glass ampule containing the required amounts of monomer and initiator. The ampule was degassed three times by the usual freezing and thawing technique under a vacuum and then sealed off. It was then placed in a thermostat-regulated area at the required temperature. After a predetermined reaction time, the polymer was precipitated by pouring the reaction mixture into a large excess of hexane containing a small amount of 4-tert-butylpyrocatechol as an inhibitor.

\section{Measurements}

MALDI-TOF-MS spectra were acquired in positive linear mode using an Axima-CFR time-of-flight mass spectrometer (Shimadzu/Kratos, Manchester, UK) with a pulsed $N_{2}$ laser $(337 \mathrm{~nm}) .^{14,17}$ The allyl polymer $\left(2.0 \mathrm{mg} \mathrm{ml}^{-1}\right)$, DHBA matrix $\left(20 \mathrm{mg} \mathrm{ml}^{-1}\right)$ and NaI cationizing agent $\left(1.0 \mathrm{mg} \mathrm{ml}^{-1}\right)$ were dissolved in THF. Thereafter, $0.5 \mu$ from each of these solutions was deposited on a stainless sample target by the overlayer method as follows: first deposition, matrix solution; second, cationizing agent solution and third, polymer solution. Analyte ions were accelerated at $20 \mathrm{kV}$ under delayed extraction conditions. Sodiated ions of PEG $\left(M_{\mathrm{w}}=2000 \mathrm{Da}\right)$ were used for calibration.

Size-exclusion chromatography (SEC) measurements were carried out at $40{ }^{\circ} \mathrm{C}$ in THF using a two-column Shodex KF-802.5 and -803 (Showa Denko, Tokyo, Japan), at polymer concentrations of $0.1-0.5 \%(\mathrm{w} / \mathrm{v})$ and at a flow rate of $1 \mathrm{ml} \mathrm{min}^{-1}$. SEC curves monitored with a differential refractometer were analyzed using the calibration curve obtained with standard samples of monodispersed polystyrene to estimate the molecular weight.

${ }^{1} \mathrm{H}$ NMR spectra were recorded on a JEOL AL-400 (Jeol, Tokyo, Japan). $\mathrm{NMR}$ measurements were carried out at $400 \mathrm{MHz}$ in $\mathrm{CDCl}_{3}$ at $30^{\circ} \mathrm{C}$.

\section{RESULTS AND DISCUSSION}

Identification of oligomeric poly $(\mathrm{ABz})$ with $\mathrm{DCPO}$ involving its end groups

For a long time, we have been concerned with the polymerization of multiallyl monomers, typically DAP; ${ }^{18}$ thus, $\mathrm{ABz}$ as a mono-ene counterpart of DAP was polymerized with DCPO as an initiator at elevated temperatures. DCPO underwent thermal decomposition to produce two primary cumyloxy radicals, as shown in Equation (1), subsequently followed by $\beta$-scission of a cumyloxy radical to yield a secondary methyl radical and acetophenone, as shown in Equation (2): $:^{15,16,19}$

$$
\begin{aligned}
& \left(\mathrm{C}_{6} \mathrm{H}_{5}\left(\mathrm{CH}_{3}\right)_{2} \mathrm{CO}\right)_{2} \rightarrow 2 \mathrm{C}_{6} \mathrm{H}_{5}\left(\mathrm{CH}_{3}\right)_{2} \mathrm{CO} . \\
& \mathrm{C}_{6} \mathrm{H}_{5}\left(\mathrm{CH}_{3}\right)_{2} \mathrm{CO} \cdot \rightarrow \mathrm{CH}_{3} \cdot+\mathrm{C}_{6} \mathrm{H}_{5} \mathrm{COCH}_{3}
\end{aligned}
$$

In general, the driving force for the $\beta$-scission reaction of the alkoxy radical is the reduced energy of the alkyl radical that is produced, compared with that of the oxygen-centered radical. Thus, $\beta$-scission is less favored when a higher energy methyl radical is generated. Methyl and oxygen-centered radicals have higher energies than other alkyl radicals; therefore, the peroxides that produce them are generally preferred for use in applications requiring high-energy radicals for hydrogen abstraction reactions; for example, polyolefin cross-linking. However, in applications in which hydrogen abstraction is not desired, such as vinyl monomer polymerization and copolymerization, peroxides that generate alkyl radicals having lower energies than the methyl radical should be selected. ${ }^{15}$ We are interested in the elucidation of the initiation mechanism of $\mathrm{ABz}$ polymerization using $\mathrm{DCPO}$ as an initiator at elevated temperatures because DCPO is commercially important, being commonly used for curing DAP resins. ${ }^{20}$

As the $\beta$-scission reaction of the alkoxy radical is, to the best of our knowledge, less favored, most work on alkoxy radicals as initiating species in polymerizations has concentrated on the chemistry of $t$-butoxy radicals. ${ }^{19}$ In a polymerization reaction, $t$-butoxy radicals may add to the double bond of a monomer to initiate polymerization, abstract a hydrogen from the monomer or another component to afford a new radical species and undergo $\beta$-scission to yield a methyl radical. The relative importance of these processes depends on the specified polymerization system. $t$-Butoxy radicals are slightly electrophilic. $^{21}$ However, with allyl methacrylate ${ }^{22}$ and allyl acrylate, ${ }^{23}$ the additional selectivity of $t$-butoxy radicals into two types of double bonds was markedly more favorable to the (meth)acrylic double bond than to the allylic double bond and, strikingly, allylic hydrogen abstraction predominated compared with addition.

Considering a renewed reaction mechanism that yields oligomers in the polymerization of $\mathrm{AAc},{ }^{14}$ the free-radical polymerization of $\mathrm{ABz}$ with DCPO could proceed as follows:

\begin{tabular}{ll} 
Initiation & \multicolumn{1}{c}{$\mathrm{I} \rightarrow 2 \mathrm{R}}$. \\
& $\mathrm{R} \cdot+\mathrm{M} \rightarrow \mathrm{M} \cdot$ \\
Propagarion & $\mathrm{M} \cdot+\mathrm{M} \rightarrow \mathrm{M} \cdot$ \\
Chain transfer & $\mathrm{M} \cdot+\mathrm{M} \rightarrow \mathrm{P}+\mathrm{M}^{*}$. \\
Re - initiation & $\mathrm{M}^{*} \cdot+\mathrm{M} \rightarrow \mathrm{M} \cdot$ \\
Termination & $\mathrm{M} \cdot+\mathrm{M}^{*} \cdot \rightarrow \mathrm{P}$ \\
& $\mathrm{M}^{*} \cdot+\mathrm{M}^{*} \cdot \rightarrow \mathrm{M}^{*}-\mathrm{M}^{*}$
\end{tabular}

where $\mathrm{I}$ is DCPO, R- the cumyloxy or methyl radical, $\mathrm{M}$ an $\mathrm{ABz}$ monomer, $\mathrm{M}$ - the oligomeric growing polymer radical, $\mathrm{P}$ the oligomeric poly $(\mathrm{ABz})$ produced and $\mathrm{M}^{*}$. the monomeric allylic radical formed by the abstraction of an allylic hydrogen from the $\mathrm{ABz}$ monomer.

According to the above reaction scheme, we should observe the specific MALDI-TOF-MS spectrum with a number of peaks assignable to oligomeric poly $(\mathrm{ABz}) \mathrm{s}$ of different degrees of polymerization $(n)$, with $\mathrm{R}$ or $\mathrm{M}^{*}$ as the initial end group and $\mathrm{H}_{\text {or }} \mathrm{M}^{*}$ as the terminal end group. For example, all possible molecular formulae of poly $(\mathrm{ABz}) \mathrm{s}$ $(n=8)$ could be depicted as follows: $\mathrm{C}_{9} \mathrm{H}_{11} \mathrm{O}(\mathrm{ABz})_{8} \mathrm{H}(\mathbf{A})$ (1433.70); $\mathrm{C}_{9} \mathrm{H}_{11} \mathrm{O}(\mathrm{ABz})_{8} \mathrm{CH}_{2} \mathrm{CH}=\mathrm{CHOCOC}_{6} \mathrm{H}_{5}$ (B) (1593.87); $\mathrm{CH}_{3}(\mathrm{ABz})_{8} \mathrm{H}$ (C) (1313.55); $\mathrm{CH}_{3}(\mathrm{ABz})_{8} \mathrm{CH}_{2} \mathrm{CH}=\mathrm{CHOCOC}_{6} \mathrm{H}_{5}$ (D) (1473.72); $\mathrm{C}_{6} \mathrm{H}_{5} \mathrm{COOCH}=\mathrm{CHCH}_{2}(\mathrm{ABz})_{8} \mathrm{H}(\mathbf{E})$ (1459.69) and $\mathrm{C}_{6} \mathrm{H}_{5} \mathrm{COOCH}=$ $\mathrm{CHCH}_{2}(\mathrm{ABz})_{8} \mathrm{CH}_{2} \mathrm{CH}=\mathrm{CHOCOC}_{6} \mathrm{H}_{5} \quad$ (F) (1619.86) (figures in parentheses denote the corresponding molecular weight).

The bulk polymerization of $\mathrm{ABz}$ was carried out using $0.1 \mathrm{moll}^{-1}$ DCPO for $20 \mathrm{~min}$ at $130^{\circ} \mathrm{C}$, although the half-life of DCPO is about $120 \mathrm{~min}$. Figure 1 shows the SEC curve of oligomeric poly $(\mathrm{ABz})$ obtained at a conversion of $12.6 \%$ as a typical example. The number-average molecular weight $\left(M_{\mathrm{n}}\right)$ and molecular weight distribution $\left(M_{\mathrm{w}} / M_{\mathrm{n}}\right)$ of the resulting poly $(\mathrm{ABz})$ were estimated to be 3770 and 


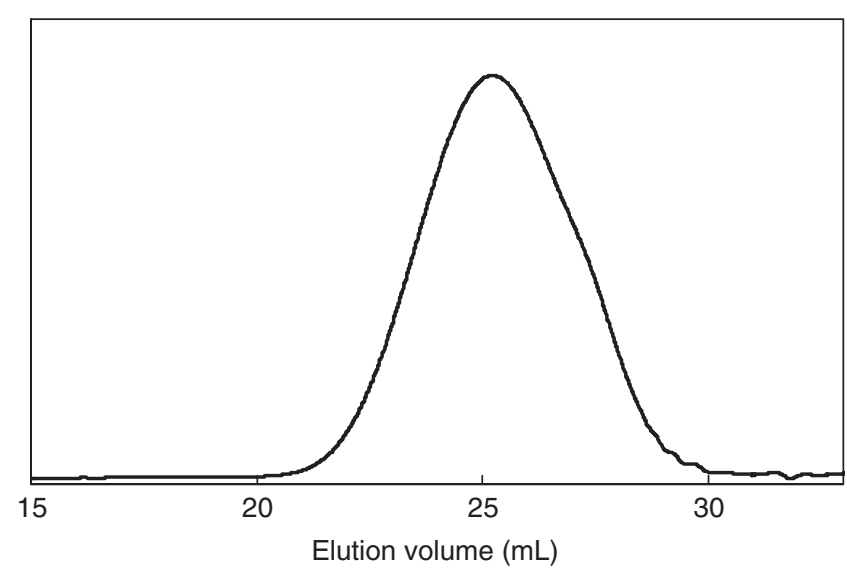

Figure $1 \mathrm{SEC}$ curve of oligomeric poly(ABz) obtained at a conversion of $12.6 \%$ in the bulk polymerization of $\mathrm{ABz}$ using $0.1 \mathrm{~mol} \mathrm{I}^{-1} \mathrm{DCPO}$ for $20 \mathrm{~min}$ at $130^{\circ} \mathrm{C}$.

1.51 , respectively, by SEC. It should be noted that the polymerization result obtained with a remarkably large amount of initiator was required for discussing any contribution of primary cumyloxy or secondary methyl radicals to the initiation reaction for the following reason. At a low initiator concentration, the reinitiation reaction of monomeric allyl radicals would predominantly occur, ${ }^{4}$ and consequently, the A- or $\mathbf{C}$-series peaks that are due to the cumyloxy or methyl radical initiation would be observed only weakly compared with the E-series peaks that are due to the reinitiation reaction of monomeric allyl radicals.

Figure 2 shows the MALDI-TOF-MS spectrum of poly $(\mathrm{ABz})$ obtained at a conversion of $12.6 \%$. Notably, both the addition to the double bond of a monomer and the abstraction reaction of an allylic hydrogen from monomers by primary cumyloxy radicals are bimolecular. However, the $\beta$-scission reaction of a cumyloxy radical to result in a secondary methyl radical and acetophenone, as shown in Equation (2) is unimolecular. Therefore, we carefully checked the influence of conversion on MALDI-TOF-MS spectra of oligomeric poly $(\mathrm{ABz}) \mathrm{s}$, but no significant difference was observed, although the polymerization was carried out in bulk. As can be seen in Figure 2, a simple spectrum was observed, as opposed to our expectation that a number of peaks (A- to F-series) could appear according to the above reaction scheme. Thus, the striking peaks in the mass spectrum of poly $(\mathrm{ABz})$ corresponded only to $\mathrm{C}$ - and E-series peaks, although the spectrum of the oligomeric poly $(\mathrm{ABz})$ in the presence of $\mathrm{NaI}$ exhibited a series of ions repeating at an interval of $162.19 \mathrm{U}$, corresponding to the $\mathrm{ABz}$ repeat unit. Most strikingly, A-series peaks with cumyloxy $\mathrm{C}_{9} \mathrm{H}_{11} \mathrm{O}$ as the initial end group did not appear at all.

The peaks with highest relative intensity (E-series) were assigned to the $\mathrm{Na}^{+}$adduct ions of poly $(\mathrm{ABz}) \mathrm{s}$, with degrees of polymerization from 7 to 9 , along with $M^{\star}$. These were introduced by the reinitiation reaction of a monomeric allyl radical as the initial end group and $\mathrm{H}$ as the terminal end group $\left(161.18+\left(162.19 n+22.98\left(\mathrm{Na}^{+}\right)\right)+1.01\right)$ (poly $\left.(\mathrm{ABz}) \mathrm{s} ; \mathrm{C}_{6} \mathrm{H}_{5} \mathrm{COOCH}=\mathrm{CHCH}_{2}-\left(\mathrm{CH}_{2}-\mathrm{CH}\left(\mathrm{CH}_{2} \mathrm{OCOC}_{6} \mathrm{H}_{5}\right)\right)_{n}-\mathrm{H}\right)$. This clearly supports the significance of monomer chain transfer as an allylic hydrogen abstraction in growing polymer radicals from monomers. In addition, the monomeric allyl radical could reinitiate to generate a new growing polymer radical at an elevated temperature.

The peaks with the second highest relative intensity (C-series) were assigned to the $\mathrm{Na}^{+}$adduct ions in the poly $(\mathrm{ABz}) \mathrm{s}$, with degrees of polymerization from 8 to 10 , along with $\mathrm{CH}_{3}$. This was introduced by the initiation reaction of methyl radical generation through $\beta$-scission

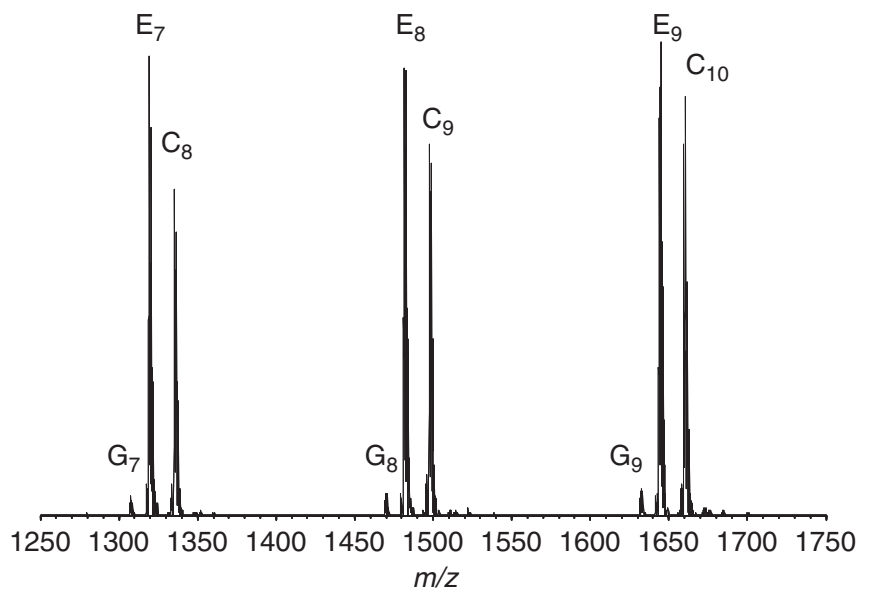

Figure 2 MALDI-TOF-MS spectrum of oligomeric poly(ABz) (see Figure 1).

of a cumyloxy radical as the initial end group and $\mathrm{H}$ as the terminal end group $\left(15.03+\left(162.19 n+22.98\left(\mathrm{Na}^{+}\right)\right)+1.01\right)(\operatorname{poly}(\mathrm{ABz}) \mathrm{s}$; $\left.\mathrm{CH}_{3}-\left(\mathrm{CH}_{2}-\mathrm{CH}\left(\mathrm{CH}_{2} \mathrm{OCOC}_{6} \mathrm{H}_{5}\right)\right)_{n}-\mathrm{H}\right)$. This clearly shows the significance of $\beta$-scission of a cumyloxy radical in generating a methyl radical as shown by Equation (2).

Weak G-series peaks having a lower mass unit, 12, corresponding to one carbon atom, than E-series peaks, were also clearly observed. This will be discussed below in connection with the intramolecular (backbiting) hydrogen abstraction to form mid-chain radicals, which subsequently undergo $\beta$-scission of the main chain, resulting in oligomeric poly $(\mathrm{ABz})$ with a terminal $=\mathrm{CH}_{2}$ group and a new radical with a high reinitiation reactivity (see Equation 9).

Here it should be recalled that DCPO is one of the typical organic peroxides used as initiators to generate radicals at elevated temperatures and thus $\mathrm{ABz}$ polymerization with DCPO was accomplished at $130{ }^{\circ} \mathrm{C}$. Because fragmentation reactions are generally favored at elevated temperatures, ${ }^{19} \beta$-scission of the resulting cumyloxy radical might be promoted. Accordingly, $\mathrm{ABz}$ polymerizations were conducted at $80,90,100,110,120$ and $140{ }^{\circ} \mathrm{C}$. The spectra obtained at the lowest temperature $\left(80^{\circ} \mathrm{C}\right)$ and the highest temperature $\left(140{ }^{\circ} \mathrm{C}\right)$ are shown in Figure 3. In both cases, C- and E-series peaks were observed strongly, although A-series peaks with cumyloxy $\mathrm{C}_{9} \mathrm{H}_{11} \mathrm{O}$ as the initial end group appeared only slightly at $80^{\circ} \mathrm{C}$. The peaks with the highest relative intensity changed from $\mathbf{E}$-series to $\mathbf{C}$-series at $140{ }^{\circ} \mathrm{C}$. In addition, new, small peaks (I- and J-series) appeared at $140^{\circ} \mathrm{C}$. This will be discussed below in connection with the $\beta$-scission of growing polymer radicals through addition-fragmentation transfer, which leads to the formation of oligomers with a terminal allyl group. ${ }^{24}$

\section{Allylic hydrogen abstraction from the $\mathrm{ABz}$ monomer by cumyloxy radical}

In the polymerization of $\mathrm{ABz}$ with $\mathrm{DCPO}$, the cumyloxy radical generated may add to the double bond of $\mathrm{ABz}$, abstract allylic hydrogen from $\mathrm{ABz}$ to afford monomeric allyl radical, and undergo $\beta$-scission to yield a methyl radical and acetophenone as shown in Equation (2). The aforementioned results show that the cumyloxy radical added little directly to the double bond. A-series peaks with cumyloxy $\mathrm{C}_{9} \mathrm{H}_{11} \mathrm{O}$ as the initial end group were observed only slightly at $80^{\circ} \mathrm{C}$ (see Figure $3 \mathrm{a}$ ), although their $\beta$-scission occurred significantly. We investigated the ability of cumyloxy radicals to abstract allylic hydrogen from $\mathrm{ABz}$ monomers. We did this because $t$-butoxy 
a
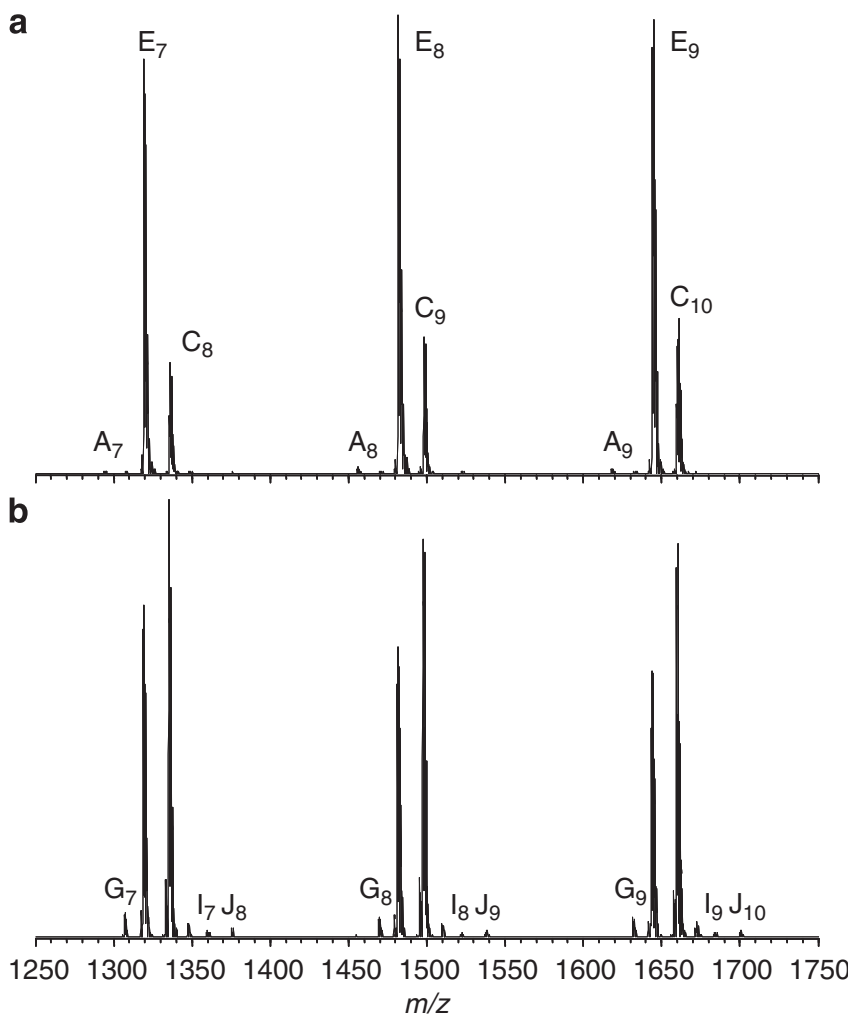

Figure 3 MALDI-TOF-MS spectra of oligomeric poly(ABz)s obtained in the bulk polymerizations of $\mathrm{ABz}$ : (DCPO), temperature, time, conversion, $M_{\mathrm{n}}$; (a) $0.4 \mathrm{moll}^{-1}, 80^{\circ} \mathrm{C}, 1260 \mathrm{~min}, 8.5 \%, 5090$; (b) $0.1 \mathrm{moll}^{-1}, 140^{\circ} \mathrm{C}$ $20 \mathrm{~min}, 31.9 \%, 3070$.

radicals, as typical oxygen-centered radicals, easily abstracted allylic hydrogen from allyl methacrylate ${ }^{22}$ and allyl acrylate; ${ }^{23}$ this allylic hydrogen abstraction predominated when compared with addition to the double bond of the allyl group. Moreover, Walling and Thaler ${ }^{25}$ reported that allylic hydrogen abstraction, rather than addition, was the preferred reaction of $t$-butoxy radicals with many olefins.

The abstraction of a hydrogen from an $\mathrm{ABz}$ monomer by a cumyloxy radical should afford not only a monomeric allyl radical but also 2-phenyl-2-propanol. Thus, the generation of 2-phenyl-2propanol was checked by ${ }^{1} \mathrm{H}$ NMR spectrometry. $\mathrm{ABz}$ polymerization was conducted in bulk using $0.1 \mathrm{moll}^{-1} \mathrm{DCPO}$ at $140{ }^{\circ} \mathrm{C}$. As the halflife of DCPO at $140{ }^{\circ} \mathrm{C}$ is about $37 \mathrm{~min}$, we performed a dead-end polymerization $^{26}$ for $20 \mathrm{~h}$ to reach a conversion of $78 \%$. The polymerization solution was then subjected to ${ }^{1} \mathrm{H}$ NMR measurements (see Figure 4a). Notably, an intense peak assignable to acetoxy protons of acetophenone generated by $\beta$-scission was observed clearly at 2.61 p.p.m., whereas a weak peak assignable to methyl protons of 2-phenyl-2-propanol generated by allylic hydrogen abstraction appeared at 1.59 p.p.m. We estimated the molar ratio of acetophenone/2-phenyl-2-propanol to be 80:20 as follows. The polymerization solution was poured into a large excess of hexane containing a small amount of 4-tert-butylpyrocatechol as an inhibitor to precipitate poly $(\mathrm{ABz})$. The supernatant solution was then evaporated to remove hexane, and the residue was subjected to ${ }^{1} \mathrm{H}$ NMR measurements (see Figure $4 \mathrm{~b}$ ). This is in line with the result that, at $140{ }^{\circ} \mathrm{C}$, the peaks with the highest relative intensity changed from $\mathbf{E}$-series to $\mathbf{C}$-series, with $\mathrm{CH}_{3}$ as the initial end group, as introduced by the initiation reaction of methyl radicals generated by $\beta$-scission of cumyloxy radicals (see Figure $3 \mathrm{~b}$ ).
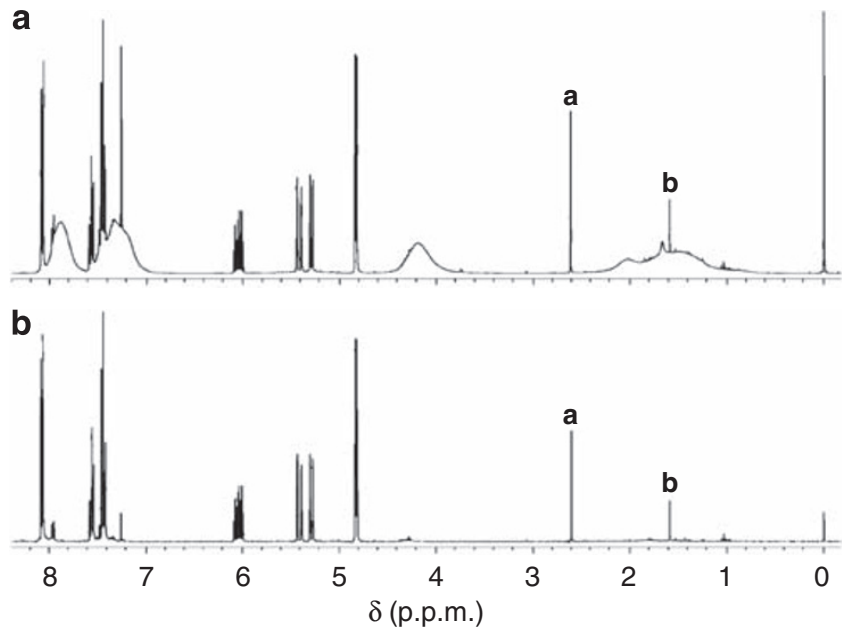

Figure 4 (a) ${ }^{1} \mathrm{H}$ NMR spectrum of the polymerization solution obtained at a conversion of $78 \%$ in the bulk polymerization of $A B z$ using $0.1 \mathrm{moll}^{-1}$ DCPO for $20 \mathrm{~h}$ at $140^{\circ} \mathrm{C}$. (b) ${ }^{1} \mathrm{H}$ NMR spectrum of the residue after removing poly $(\mathrm{ABz})$ from the polymerization solution.

Because no A-series peaks with cumyloxy as the initial end group were observed in Figure $3 \mathrm{~b}$ at $140{ }^{\circ} \mathrm{C}, 20 \mathrm{~mol} \%$ of cumyloxy radicals generated by the thermal decomposition of DCPO presumably preferentially abstracted allylic hydrogen from the $\mathrm{ABz}$ monomer because the allylic hydrogen abstraction was the preferred reaction of the $t$-butoxy radical with many olefins. ${ }^{25}$ Related to this, Watanabe et al. ${ }^{27}$ reported the temperature dependence of initiation reactions of oxygen-centered radicals using an $\alpha$-methylstyrene dimer as a radical trapping agent; that is, the addition $/ \beta$-scission ratio of cumyloxy radicals was determined to be $40.8: 59.2$ at $140{ }^{\circ} \mathrm{C}$, although the $\alpha$-methylstyrene dimer was assumed to be a model compound of styrene.

\section{Generalization of the predominant methyl radical initiation} preceded by $\beta$-scission of cumyloxy radicals to common alkoxys As mentioned above, we found by chance that almost no direct contribution of cumyloxy radicals to the initiation reaction was observed in the polymerization of $\mathrm{ABz}$ with $\mathrm{DCPO}$ as one of the typical initiators at elevated temperatures. This prompted us to attempt the generalization of the specific initiation of cumyloxy radicals to common alkoxy radicals; that is, the predominant methyl radical initiation was preceded by $\beta$-scission of alkoxy radicals. Thus, $\mathrm{ABz}$ polymerizations were performed using $\mathrm{BPOB}$ and $\mathrm{DBPO}$ as initiators that afford $t$-butoxy radicals by their thermal decomposition.

Notably, BPOB undergoes thermal decomposition to produce two kinds of primary benzoyloxy and t-butoxy radicals, as shown in Equation (3), which is subsequently followed by $\beta$-scission of both benzoyloxy and $t$-butoxy radicals to yield secondary phenyl and methyl radicals, respectively, and carbon dioxide and acetone, as shown in Equations (4) and (5):

$$
\begin{aligned}
& \mathrm{C}_{6} \mathrm{H}_{5} \mathrm{C}(\mathrm{O}) \mathrm{OOC}\left(\mathrm{CH}_{3}\right)_{3} \rightarrow \mathrm{C}_{6} \mathrm{H}_{5} \mathrm{COO} \cdot+\left(\mathrm{CH}_{3}\right)_{3} \mathrm{CO} \cdot \\
& \mathrm{C}_{6} \mathrm{H}_{5} \mathrm{COO} \cdot \rightarrow \mathrm{C}_{6} \mathrm{H}_{5} \cdot+\mathrm{CO}_{2} \\
& \left(\mathrm{CH}_{3}\right)_{3} \mathrm{CO} \cdot \rightarrow \mathrm{CH}_{3} \cdot+\mathrm{CH}_{3} \mathrm{COCH}_{3}
\end{aligned}
$$

Figure 5 shows the MALDI-TOF-MS spectrum of poly $(\mathrm{ABz})$ obtained in the bulk polymerization of $\mathrm{ABz}$ using $0.1 \mathrm{moll}^{-1} \mathrm{BPOB}$ for $20 \mathrm{~min}$ at $130^{\circ} \mathrm{C}$, although the half-life of BPOB is about $36 \mathrm{~min}$. It should be 


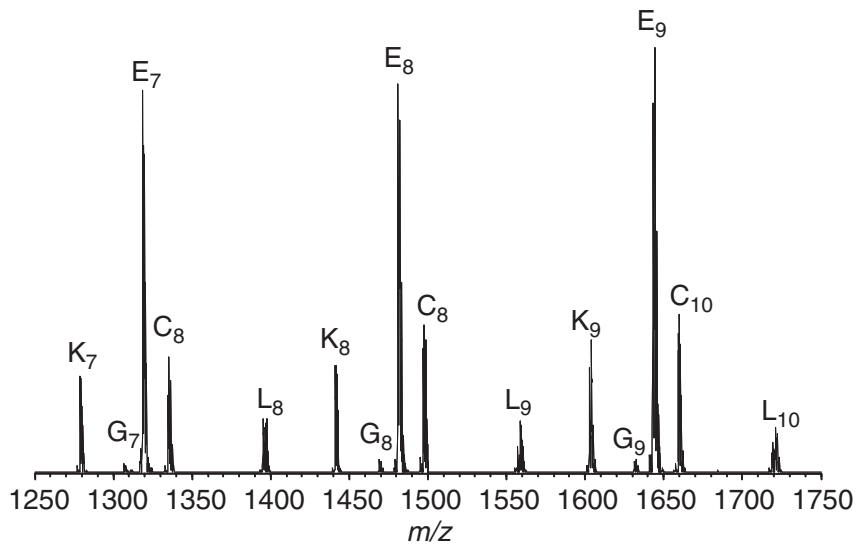

Figure 5 MALDI-TOF-MS spectrum of oligomeric poly $(\mathrm{ABz})\left(M_{\mathrm{n}}=3420\right)$ obtained at a conversion of $16.6 \%$ in the bulk polymerization of $\mathrm{ABz}$ using $0.1 \mathrm{moll}^{-1} \mathrm{BPOB}$ for $20 \mathrm{~min}$ at $130^{\circ} \mathrm{C}$.

noted that $t$-butoxy radicals could be generated as a counterpart of benzoyloxy radicals in the thermal decomposition of BPOB. Thus, $\mathbf{K}$ - and $\mathbf{L}$-series peaks with benzoyloxy $\mathrm{C}_{7} \mathrm{H}_{5} \mathrm{O}_{2}$ and phenyl $\mathrm{C}_{6} \mathrm{H}_{5}$ as the initial end groups, respectively, could newly appear. Clearly, both peaks were observed, although only weak L-series peaks appeared. Notably, any A-series peaks with $t$-butoxy $\mathrm{C}_{4} \mathrm{H}_{9} \mathrm{O}$ as the initial end group did not appear.

As with DCPO, DBPO undergoes thermal decomposition to produce two primary $t$-butoxy radicals, as shown in Equation (6), subsequently followed by $\beta$-scission of a $t$-butoxy radical to result in a secondary methyl radical and acetone, as shown in Equation (7):

$$
\begin{aligned}
& \left(\left(\mathrm{CH}_{3}\right)_{3} \mathrm{CO}\right)_{2} \rightarrow 2\left(\mathrm{CH}_{3}\right)_{3} \mathrm{CO} . \\
& \left(\mathrm{CH}_{3}\right)_{3} \mathrm{CO} \cdot \rightarrow \mathrm{CH}_{3} \cdot+\mathrm{CH}_{3} \mathrm{COCH}_{3}
\end{aligned}
$$

Figure 6 shows the MALDI-TOF-MS spectrum of poly(ABz) obtained in the bulk polymerization of $\mathrm{ABz}$ using $0.1 \mathrm{moll}^{-1} \mathrm{DBPO}$ for $30 \mathrm{~min}$ at $130{ }^{\circ} \mathrm{C}$, although the half-life of DBPO is about $300 \mathrm{~min}$. Any peaks with $t$-butoxy $\mathrm{C}_{4} \mathrm{H}_{9} \mathrm{O}$ as the initial end group were not observed again at all, in accordance with our expectation.

It was conclusively confirmed that the initiation by methyl radical generated by $\beta$-scission of alkoxy radicals occurred predominantly in the polymerization of $\mathrm{ABz}$ with organic peroxide initiators at elevated temperatures.

Specific polymerization mechanism involving additionfragmentation chain transfer and $\beta$-scission of mid-chain radicals Addition-fragmentation chain transfer has been reported recently. ${ }^{28}$ Even in allyl polymerization, the formation of oligomers with a terminal allyl group may be observed as a result of the occurrence of $\beta$-scission of growing polymer radicals, although Gaylord et al. ${ }^{24}$ reported the $\beta$-scission of growing polymer radicals through additionfragmentation transfer in the polymerization of AAc. Thus, a terminal allyl group characteristic of the I-series $(15.03+(162.19 n+22.98$ $\left.\left.\left(\mathrm{Na}^{+}\right)\right)+41.07\right) \quad\left(\operatorname{poly}(\mathrm{ABz}) \mathrm{s} ; \quad \mathrm{CH}_{3}-\left(\mathrm{CH}_{2}-\mathrm{CH}\left(\mathrm{CH}_{2} \mathrm{OCOC}_{6} \mathrm{H}_{5}\right)\right)_{n}-\right.$ $\left.\mathrm{CH}_{2} \mathrm{CH}=\mathrm{CH}_{2}\right)$ and J-series $\left(161.18+\left(162.19 n+22.98\left(\mathrm{Na}^{+}\right)\right)+\right.$ 41.07) (poly $(\mathrm{ABz}) \mathrm{s} ; \quad \mathrm{C}_{6} \mathrm{H}_{5} \mathrm{COOCH}=\mathrm{CHCH}_{2}-\left(\mathrm{CH}_{2}-\mathrm{CH}\left(\mathrm{CH}_{2} \mathrm{O}-\right.\right.$ $\left.\left.\mathrm{COC}_{6} \mathrm{H}_{5}\right)\right)_{n}-\mathrm{CH}_{2} \mathrm{CH}=\mathrm{CH}_{2}$ ) could be introduced by the following

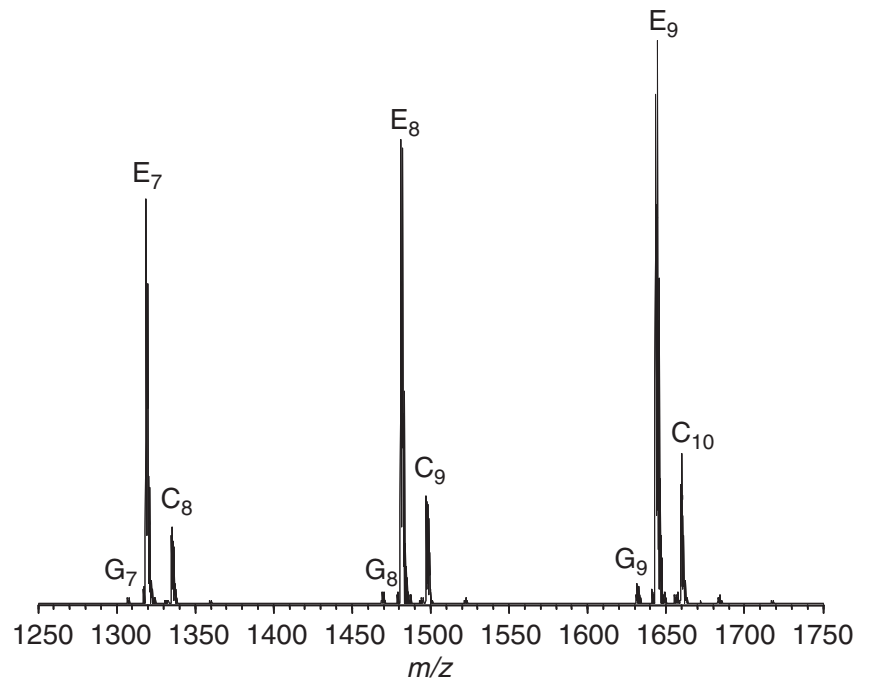

Figure 6 MALDI-TOF-MS spectrum of oligomeric poly(ABz) $\left(M_{n}=4120\right)$ obtained at a conversion of $7.2 \%$ in the bulk polymerization of $A B z$ using $0.1 \mathrm{moll}^{-1} \mathrm{DBPO}$ for $30 \mathrm{~min}$ at $130^{\circ} \mathrm{C}$.

chain termination involving $\beta$-scission of growing polymer radicals through addition-fragmentation transfer:<smiles>C=[W]C=CC(=O)OCC(=C)CNCC(CN[M]CC(=O)O)COC(C)=O</smiles>

Notably, this kind of $\beta$-scission of growing polymer radicals was ruled out in the reaction scheme proposed by Litt and Eirich, ${ }^{13}$ although its significance has been shown in several reports. ${ }^{24,29-32}$ However, appreciable I- and $\mathbf{J}$-series peaks were not observed in $\mathrm{ABz}$ polymerization at $80^{\circ} \mathrm{C}$, although weak peaks were observed at $140^{\circ} \mathrm{C}$ (see Figure 2b). The result shown in Equation 8 could be enhanced at elevated temperatures and at a lower monomer concentration. A more detailed discussion of addition-fragmentation chain transfer will be given elsewhere.

Finally, we will briefly refer to the existence of the G-series (149.17 $\left.+\left(162.19 n+22.98\left(\mathrm{Na}^{+}\right)\right)+1.01\right)\left(\operatorname{poly}(\mathrm{ABz}) s ; \mathrm{C}_{6} \mathrm{H}_{5} \mathrm{COOCH}_{2} \mathrm{CH}_{2}-\right.$ $\left.\left(\mathrm{CH}_{2}-\mathrm{CH}\left(\mathrm{CH}_{2} \mathrm{OCOC}_{6} \mathrm{H}_{5}\right)\right)_{n}-\mathrm{H}\right)$. As discussed in our preceding article, ${ }^{14}$ the intramolecular (backbiting) hydrogen abstraction that forms mid-chain radicals, which subsequently undergo $\beta$-scission of the main chain, resulting in poly $(\mathrm{ABz})$ with a terminal $=\mathrm{CH}_{2}$ group, and a new radical $\mathrm{C}_{6} \mathrm{H}_{5} \mathrm{COOCH}_{2} \mathrm{CH}_{2}$ with high reinitiation reactivity, leads to the appearance of $\mathrm{G}$-series peaks:

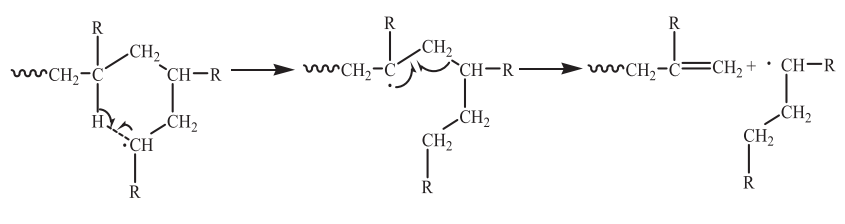

$\mathbf{H}$-series peaks $\left(15.03\right.$ or $\left.\ldots+\left(162.19 n+22.98\left(\mathrm{Na}^{+}\right)\right)+175.21\right)$ (poly $(\mathrm{ABz}) \mathrm{s} ; \mathrm{X}-\left(\mathrm{CH}_{2}-\mathrm{CH}\left(\mathrm{CH}_{2} \mathrm{OCOC}_{6} \mathrm{H}_{5}\right)\right)_{n} \mathrm{CH}_{2}-\mathrm{C}\left(\mathrm{CH}_{2} \mathrm{OCOC}_{6} \mathrm{H}_{5}\right)=$ $\left.\mathrm{CH}_{2}\right)\left(\mathrm{X}=\mathrm{CH}_{3}, \mathrm{C}_{6} \mathrm{H}_{5} \mathrm{COOCH}=\mathrm{CHCH}_{2}, \mathrm{C}_{6} \mathrm{H}_{5} \mathrm{COO}, \mathrm{C}_{6} \mathrm{H}_{5}\right.$ or 
$\mathrm{C}_{6} \mathrm{H}_{5} \mathrm{COOCH}_{2} \mathrm{CH}_{2}$ ) could be observed as corresponding partners of the $\mathbf{G}$-series, although they were quite weak.

\section{CONCLUSIONS}

In allyl polymerization, it is conceivable that allyl monomers polymerize only with difficulty and yield polymers of medium molecular weight or oligomers, because of 'degradative monomer chain transfer'. The resulting monomeric allyl radical is less active and/or less inclined to initiate a new polymer chain because of an ability to stabilize itself by resonance, the monomer chain transfer being essentially a termination reaction. Thus, the elucidation of reinitiation reactivity of monomeric allyl radicals is necessary for a deep understanding of allyl polymerization. In the course of our investigation, which was concerned with the temperature dependence of the reinitiation reactivity of resonance-stabilized monomeric allyl radicals and was especially focused on polymerization behavior at elevated temperatures, we found by chance that any direct contribution of cumyloxy radicals to the initiation reaction was not observed in the polymerization of $\mathrm{ABz}$ with $\mathrm{DCPO}$ at elevated temperatures. This prompted us to generalize the specific initiation of cumyloxy radicals to common alkoxy radicals. It was confirmed that initiation by methyl radicals, generated by $\beta$-scission of alkoxy radicals, occurred predominantly in the polymerization of $\mathrm{ABz}$ with organic peroxide initiators at elevated temperatures.

\section{ACKNOWLEDGEMENTS}

We thank Professor Ryuichi Arakawa of Kansai University and Dr Tsuneyuki Sato, Professor Emeritus of Tokushima University, for helpful discussions. This research was financially supported by the 'High-Tech Research Center' Project for Private Universities: matching fund subsidy from the Ministry of Education, Culture, Sports, Science and Technology, 2005-2009.

1 Odian, G. Principles of Polymerization. 4th edn. 263-264 (Wiley, New York, 2004)

2 Schildknecht, C. E. Allyl Compounds and their Polymers (Wiley, New York, 1973).

3 Laible, R. C. Allyl polymerizations. Chem. Rev. 58, 807-843 (1958).

4 Volodina, V. I., Tarasov, A. I. \& Spasskii, S. Polymerisation of allyl compounds. Russ. Chem. Rev. 39, 140-155 (1970).

5 Bartlett, P. D. \& Altschul, R. Polymerization of allyl compounds. I. Factors governing the acyl peroxide-induced polymerization of allyl acetate, and the fate of the peroxide. J. Am. Chem. Soc. 67, 812-816 (1945).

6 Bartlett, P. D. \& Altschul, R. Polymerization of allyl compounds. II. Preliminary kinetic study of the peroxide-induced polymerization of allyl acetate. J. Am. Chem. Soc. 67 816-822 (1945).

7 Bartlett, P. D. \& Tate, F. A. The polymerization of allyl compounds. VI. The polymerization of ally-1,1-d2 acetate and the mechanism of its chain termination. J. Am. Chem. Soc. 75, 91-95 (1953).
8 Gaylord, N. G. \& Eirich, F. R. Allyl polymerization. II. Decomposition of benzoyl peroxide in allyl esters. J. Am. Chem. Soc. 74, 334-337 (1952).

9 Gaylord, N. G. \& Eirich, F. R. Allyl polymerization. III. Kinetics of polymerization of allyl esters. J. Am. Chem. Soc. 74, 337-342 (1952).

10 Sakurada, I. \& Takahashi, G. Allyl polymerization. I. Polymerization of allyl acetate. Kobunshi Kagaku 11, 255-260 (1954).

11 Sakurada, I. \& Takahashi, G. Allyl polymerization. II. Kinetics of polymerization of allyl acetate. Kobunshi Kagaku 11, 260-265 (1954).

12 Sakurada, I. \& Takahashi, G. Allyl polymerization. III. Effective chain transfer. Kobunshi Kagaku 11, 266-270 (1954).

13 Litt, M. \& Eirich, F. R. Polymerization of allyl acetate. J. Polym. Sci. 45, 379-396 (1960).

14 Matsumoto, A., Kumagai, T., Aota, H., Kawasaki, H. \& Arakawa, R. Reassessment of free-radical polymerization mechanism of allyl acetate based on end-group determination of resulting oligomers by MALDI-TOF-MS spectrometry. Polym. J. 41, 26-33 (2009).

15 Sanchez, J \& Myers, T. N. Polymeric Materials Encyclopedia. Vol. 7, 4927-4938 (CRC Press, Boca Raton, 1996).

16 Myers, T. N. Encyclopedia of Chemical Technology. Vol. 6, 563-600 (Wiley, New York, 2003).

17 Kumagai, T., Kagawa, C., Aota, H., Takeda, Y., Kawasaki, H., Arakawa, R. \& Matsumoto, A. Specific polymerization mechanism involving $\beta$-scission of mid-chain radical yielding oligomers in the free-radical polymerization of vinyl ethers. Macromolecules 41, 7347-7351 (2008).

18 Matsumoto, A. Polymerization of multiallyl monomers. Prog. Polym. Sci. 26, 189-257 (2001).

19 Moad, G. \& Solomon, D. H. The Chemistry of Radical Polymerization. 2nd fully revised edn. 49-166 (Elsevier, Amsterdam, 2006).

20 Laible, R. C. Encyclopedia of Chemical Technology. Vol. 1, 750 (Wiley, New York, 1964).

21 Jones, M. J., Moad, G., Rizzardo, E. \& Solomon, D. H. The philicity of tert-butoxy radicals. What factors are important in determining the rate and regiospecificity of tertbutoxy radical addition to olefins? J. Org. Chem. 54, 1607-1611 (1989).

22 Busfield, W. K., Jenkins, I. D., Thang, S. H., Rizzardo, E. \& Solomon, D. H. Initiation mechanisms in radical polymerization: reaction of tert-butoxy radicals with allyl methacrylate. Aust. J. Chem. 38, 689-698 (1985).

23 Busfield, W. K., Jenkins, I. D., Thang, S. H., Rizzardo, E. \& Solomon, D. H. Initiation mechanisms in radical polymerization: reaction of tert-butoxy radicals with allyl acrylate and with diallyl ether. J. Chem. Soc. Perkin. Trans. 1, 485-490 (1988).

24 Gaylord, N. G., Katz, M. \& Mark, H. F. Radical displacement as a termination reaction in allyl ester polymerization. J. Polym. Sci. Polym. Lett. Ed. 2, 151-155 (1964).

25 Walling, C. \& Thaler, W. Positive halogen compounds. III. Allylic chlorination with tertbutyl hypochlorite. The stereochemistry of allylic radicals. J. Am. Chem. Soc. 83, 3877-3884 (1961).

26 Odian, G. Principles of Polymerization. 4th edn. 234 (Wiley, New York, 2004).

27 Watanabe, Y., Ishigaki, H., Okada, H. \& Suyama, S. Temperature dependence of initiation reactions of oxygen-centered radicals. Polym. J. 29, 693-696 (1997).

28 Moad, G. \& Solomon, D. H. The Chemistry of Radical Polymerization. 2nd fully revised edn. 296-309 (Elsevier, Amsterdam, 2006).

29 Matsumoto, A., Tamura, I., Yamawaki, M. \& Oiwa, M. Studies of the polymerization of diallyl compounds. XXII. Polymerization of diallyl oxalate in the evolution of carbon dioxide at elevated temperatures. J. Polym. Sci. Polym. Chem. Ed. 17, 1419-1429 (1979).

30 Strumik, M. I., Krolikowski, W. \& Jankowska, M. Polymerization of diallyl phthalate at high temperatures. J. Appl. Polym. Sci. 26, 3537-3541 (1981).

31 Kostanski, L. K. \& Krolikowski, W. Bulk polymerization of diallyl benzene-dicarboxylates. I. Influence of temperature on allyl group reactivity. J. Polym. Sci. Polym. Chem. Ed. 23, 605-614 (1985).

32 Kostanski, L. K. \& Krolikowski, W. Effect of temperature on the structure of prepolymers of diallyl benzenedicarboxylates. Polymer 27, 403-408 (1986). 